\title{
Comparative Study on Dynamic Mechanical Properties and Energy Dissipation of Rocks under Impact Loads
}

\author{
Renshu Yang, ${ }^{1,2}$ Weiyu Li $\mathbb{D}^{1,3}$ and Zhongwen Yue ${ }^{3}$ \\ ${ }^{1}$ State Key Laboratory for Geomechanics and Deep Underground Engineering, \\ China University of Mining and Technology (Beijing), Beijing 100083, China \\ ${ }^{2}$ Civil and Resource Engineering School, University of Science and Technology Beijing, Beijing 100083, China \\ ${ }^{3}$ School of Mechanics and Civil Engineering, China University of Mining and Technology (Beijing), Beijing 100083, China \\ Correspondence should be addressed to Weiyu Li; wylcumtb@163.com
}

Received 3 June 2020; Revised 22 August 2020; Accepted 18 September 2020; Published 10 October 2020

Academic Editor: Denise-Penelope Kontoni

Copyright (C) 2020 Renshu Yang et al. This is an open access article distributed under the Creative Commons Attribution License, which permits unrestricted use, distribution, and reproduction in any medium, provided the original work is properly cited.

\begin{abstract}
Geological conditions are often complex during rock engineering construction (such as blasting and drilling) and usually involve rocks of several or multiple lithologies. However, comparative studies on the dynamic mechanical response of rocks of different lithologies are relatively few. To study differences in dynamic mechanical properties and energy dissipation of rocks of different lithologies, three kinds of rock that are common in rock engineering and have large differences in wave impedance were selected: red sandstone, gray sandstone, and granite. Samples of these three rocks were subjected to impact compression tests at different impact speeds, and the rock fragments after impact compression were screened to quantify the degree of fragmentation. The characteristics of stress wave propagation, dynamic stress-strain relationships, degree of fragmentation, and energy dissipation laws of the three rock types were compared and studied. The results show the following: (1) affected by the wave impedance matching relationship, the reflected waves, strain rates, and reflected energy of the three kinds of rock showed significant differences under the same incident stress wave. (2) The dynamic mechanical characteristics and energy dissipation laws of the rocks all had obvious strain rate effects, but the dynamic uniaxial compressive strength and energy dissipation density of the three rock types had different sensitivities to the strain rate. (3) The change trend of the energy utilization efficiency of the gray sandstone with incident energy was different from that of the red sandstone and granite; there was no obvious extreme point in the incident energy range. The three kinds of rock required different incident energies to reach maximum energy utilization efficiency. (4) The equivalent average fragment size of the three rock types decreased as a function of power with increasing impact velocity and energy dissipation density. (5) Under the same incident wave, although the reflection energy, transmission energy, and degree of fragmentation of the three kinds of rock showed significant differences, the differences in dissipation energy were small.
\end{abstract}

\section{Introduction}

Many engineering fields, such as blasting engineering, protection engineering, and seismic exploration, involve the propagation and attenuation of stress waves in rock masses and the deformation and destruction of rock masses under dynamic loads [1-9]. It is important to consider the inertia effect and strain rate effect of rocks [10-12], as the mechanical behavior of rocks under a dynamic load is significantly different from those under static and quasistatic loads [13-16]. At the same time, the process of stress waves acting on rocks involves the inflow, accumulation, dissipation, and outflow of energy, and energy changes throughout the entire process of rock deformation and failure. The relationship between energy consumption, fragmentation degree, and block distribution is a basic problem of rock fragmentation [17-20]. Therefore, studying the mechanical response and energy dissipation of rocks under high strain rates is of great significance to engineering fields such as rock breaking and protection. Regarding the excavation of coal mine rock tunnels, studying the dynamic mechanical properties and energy consumption of rocks can provide a basis for fine blasting, protection of surrounding rocks, optimization of blasting, and support parameters. Such investigations are 
therefore of great significance for efficient rock breaking, improving rock breaking effects, increasing tunneling speed, and ensuring safety in coal mines.

The split Hopkinson bar has the advantages of simple structure, convenient operation, accurate measurement results, and good repeatability. Therefore, it has been widely used in the investigation of the dynamic mechanical behavior of rock materials. Many scholars have used the split Hopkinson bar test device to study the dynamic strength, dynamic fracture failure, dynamic damage, and dynamic constitutive relationship of rock materials, and have obtained many meaningful conclusions [21-26]. Dong et al. investigated the fracture behavior of single-flawed rock-like material plates made of mortar, and the experimental result reveals that the dynamic strength is more sensitive to the loading rate for specimens with lower flaw angles [27]. $\mathrm{Wu}$ et al. studied the dynamic mechanical properties of transversely isotropic phyllites with different bedding angles, and the results show that both the strain rate and bedding angle clearly influence the dynamic compressive strength [28]. Han et al. investigated the thickness of filling joint effect on the dynamic response of rock specimens, the results show that the transmission coefficient, dynamic strength, and energy absorption all decrease with increasing joint thickness [29]. Ping et al. studied the dynamic mechanical properties of coal mine sandstone after high temperature cycling, and the results show that the dynamic compressive stress-strain curve of sandstone under impact loading is obviously different from that under normal temperature [30].

However, a large number of studies have mainly focused on rocks of the same lithology; comparative studies on the dynamic mechanical properties and crushing energy consumption of rocks of different lithologies are relatively few. However, as natural geological products, rock materials vary greatly in mineral composition and structural characteristics based on their genesis and geological structure. As a result, the physical and mechanical properties and deformation and failure characteristics of various rocks and even rocks of the same type are different. Geological conditions are often complex during rock engineering construction and usually involve rocks of several or multiple lithologies. In addition, blasting and excavation engineering of underground rock lanes in coal mines often involve blasting through rocks of different lithologies. The blastability of rock masses of different lithologies is necessarily different, and lithology has a great impact on the degree of wave impedance matching of explosives to rocks, which in turn affects the efficiency of explosive energy utilization. Furthermore, drilling lithologically different rocks has different requirements for rig power and speed. Therefore, it is necessary to conduct comparative study and analysis on the dynamic mechanical characteristics, energy dissipation, and stress wave propagation laws of different rock lithologies to provide some basis for the selection of explosives, optimization of blasting parameters, and development of new drilling equipment. The dynamic mechanical parameters of rocks with different lithologies can be determined by consulting relevant data. However, most tests are performed under different test conditions. Differences in test systems, specimen sizes, and loading conditions often limit the comparative study and analysis of the dynamic mechanical properties of different lithologies. In addition, the effect of stress wave propagation should be considered with respect to the dynamic mechanical properties of rocks under high strain rates. Related studies have shown that the wave impedance of rocks has a large effect on wave propagation. [31-34].

Therefore, three kinds of rock that are common in rock engineering and have large differences in wave impedance were selected. The split Hopkinson pressure bar (SHPB) test system was used to perform impact compression tests under the same test conditions. The rock fragments after impact crushing were screened to quantify the degree of fragmentation. The characteristics of stress wave propagation, dynamic stress-strain relationship, degree of fragmentation, and energy dissipation of three kinds of rock were compared and studied. The results provide a reference for the selection of blasting engineering parameters, control of surrounding rock stability, and research on the mechanism of rockburst.

\section{Experimental Material and Setup}

2.1. Sample Preparation. Three kinds of rock that are typical in rock engineering were selected for comparative experimental research: red sandstone, gray sandstone, and granite. Both the red sandstone and gray sandstone were taken from a quarry in Zigong, Sichuan, and the granite was obtained from Fangshan, Beijing. According to the test method recommended by the International Society of Rock Mechanics (ISRM) for the determination of dynamic uniaxial compressive strength of rock materials using the SHPB [35], large blocks of rock with good integrity and homogeneity were cored, cut, and processed into cylindrical specimens with sizes of $\Phi 50 \times 25 \mathrm{~mm}$. To satisfy the SHPB experiment uniformity assumption and reduce the effect of friction, a rock grinder was used to grind the two end faces and the surrounding parts of the rock samples, and the end-face nonparallelism and nonverticality were controlled within $\pm 0.02 \mathrm{~mm}$. Three groups of rock samples that met the test requirements were processed, as shown in Figure 1 .

2.2. Basic Physical and Mechanical Parameters. The P-wave velocity test system shown in Figure 2 was used to measure the P-wave velocity of the three kinds of rock. The system consisted of a pulse transceiver, a signal display, and an acoustic transducer. Static splitting tensile tests and uniaxial compression tests were performed on the three kinds of rock using the MTS rock mechanics test system. Both tests were loaded by displacement control, with loading rates of $0.02 \mathrm{~mm} / \mathrm{min}$ and $0.1 \mathrm{~mm} / \mathrm{min}$. Each rock was subjected to three repeated tests under the same loading conditions, and the tensile strength, uniaxial compressive strength, and elastic modulus of each of the three rock types were obtained. The basic physical and mechanical parameters of the three kinds of rock are shown in Table 1. 


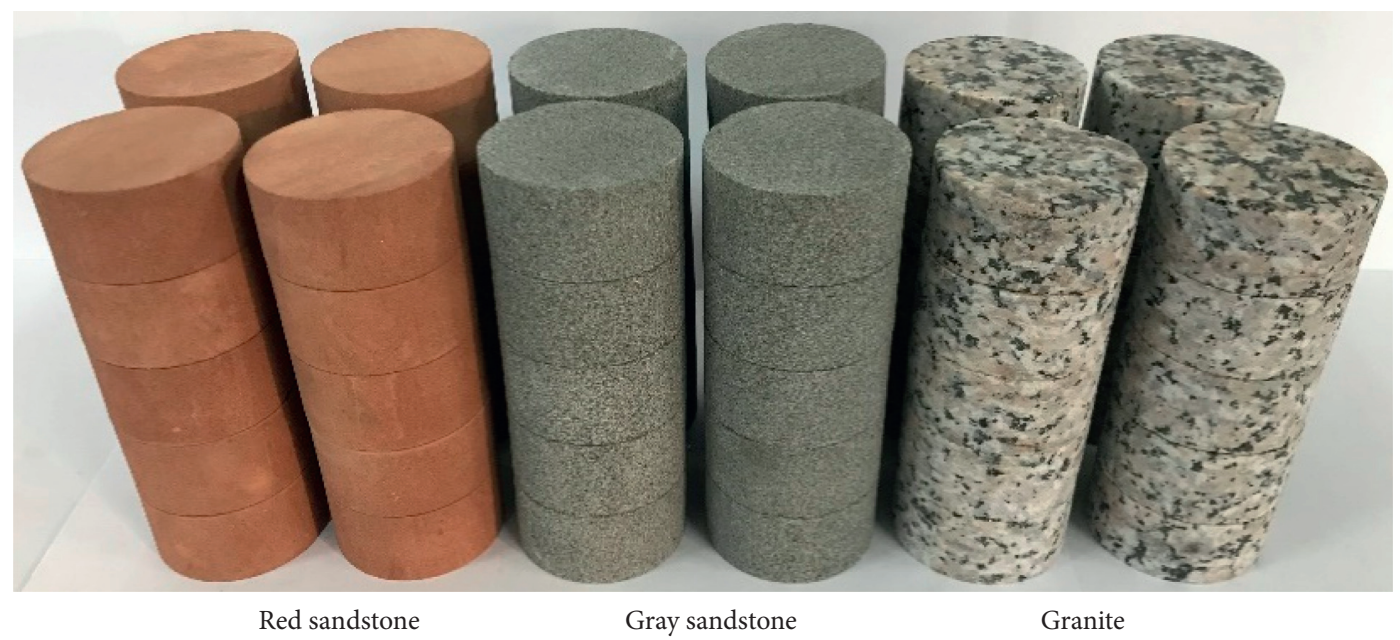

FIGURE 1: Three kinds of rock samples.

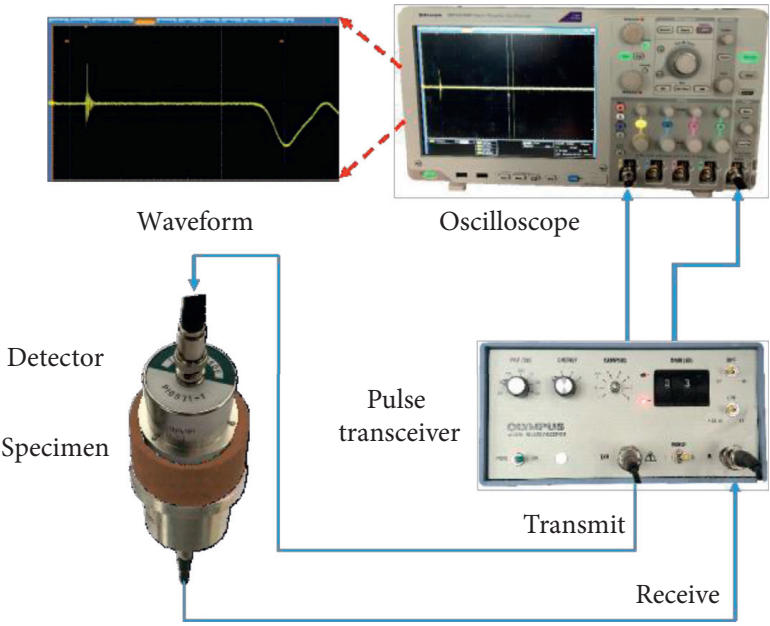

FIgURE 2: Longitudinal wave velocity test system.

2.3. SHPB Test System. According to the test method for dynamic uniaxial compressive strength of rock materials recommended by the ISRM [35], the standard SHPB test system shown in Figure 3 was used to perform uniaxial impact compression tests on the three rock types. This system is mainly composed of a launching device, speed measuring device, bars (impact bar, incident bar, transmission bar, and absorption bar), damping device, and data acquisition device. The impact bar, incident bar, and transmission bar are all cylindrical high-strength steel bars with diameters of $50 \mathrm{~mm}$, and their lengths are $300 \mathrm{~mm}$, $2,000 \mathrm{~mm}$, and $1,800 \mathrm{~mm}$. The elastic modulus of the bars is $206 \mathrm{GPa}$, and the measured P-wave velocity is $5,250 \mathrm{~m} / \mathrm{s}$. Therefore, the one-dimensional stress wave assumption was basically satisfied for the bars. In this test procedure, a rock sample is placed between the incident bar and the transmission bar. The impact bar hits the incident bar and forms an incident wave $\left(\varepsilon_{i}\right)$ in the incident bar. The incident wave travels forward and interacts with the rock sample. Because of the difference in wave impedance between the bar and the rock sample, a reflected wave $\left(\varepsilon_{r}\right)$ and a transmitted wave $\left(\varepsilon_{t}\right)$ are formed in the incident bar and the transmission bar, respectively. The incident wave, reflected wave, and transmitted wave are collected by a pair of strain gauges glued to the middle of the incident bar and the transmission bar, respectively. The strain gauges are connected to a DC-97A type superdynamic strain acquisition instrument.

2.4. Dynamic Stress Balance Verification. A cylindrical impact bar striking the incident bar directly will generate a rectangular incident wave with a steep rising edge accompanied by high-frequency oscillations. Therefore, it is difficult to achieve stress balance during dynamic loading and to meet the stress-strain uniformity assumption of the sample. According to the test method for dynamic uniaxial compressive strength of rock materials recommended by the ISRM [35], the use of waveform shaping technology can effectively increase the rising edge time of the load wave, which is beneficial to achieve force balance at both ends of the specimen during the test. At the same time, the wave shaper can effectively filter the high-frequency components of the loading wave and reduce the dispersion effect. Therefore, in the test, a thin rubber sheet is used as a wave shaper placed at the front of the incident bar, and a half-sine wave with a gentle rising edge is used as the loading wave. During dynamic loading, the stresses $\left(\sigma_{1}\right.$ and $\left.\sigma_{2}\right)$ at both ends of the specimen can be calculated with the following equation:

$$
\left.\begin{array}{c}
\sigma_{1}=\frac{A_{b} E_{b}}{A_{0}}\left(\varepsilon_{i}+\varepsilon_{r}\right) \\
\sigma_{2}=\frac{A_{b} E_{b}}{A_{0}} \varepsilon_{t}
\end{array}\right\},
$$

where $A_{b}$ and $E_{b}$ are the cross-sectional area and elastic modulus of the bar, respectively, and $A_{0}$ is the cross-sectional area of the sample.

The stress history of the two ends of a red sandstone sample at an impact speed of $8.640 \mathrm{~m} / \mathrm{s}$ is shown in Figure 4. The stress history of the two ends of the specimen during 
TABLE 1: Basic mechanical parameters of rocks.

\begin{tabular}{|c|c|c|c|c|c|c|}
\hline Rock types & $\begin{array}{l}\text { Density } \\
\left(\mathrm{g} / \mathrm{cm}^{3}\right)\end{array}$ & $\begin{array}{c}\text { P-wave velocity } \\
(\mathrm{m} / \mathrm{s})\end{array}$ & $\begin{array}{l}\text { Wave impedance } \\
\left(\mathrm{g} \cdot \mathrm{cm}^{-3} \mathrm{~m} \cdot \mathrm{s}^{-1}\right)\end{array}$ & $\begin{array}{l}\text { Tensile strength } \\
(\mathrm{MPa})\end{array}$ & $\begin{array}{l}\text { Uniaxial compressive } \\
\text { strength }(\mathrm{MPa})\end{array}$ & $\begin{array}{c}\text { Elastic modulus } \\
(\mathrm{GPa})\end{array}$ \\
\hline $\begin{array}{l}\text { Red } \\
\text { sandstone }\end{array}$ & 2.32 & 2702 & 6269 & 2.21 & 32 & 3.44 \\
\hline $\begin{array}{l}\text { Gray } \\
\text { sandstone }\end{array}$ & 2.57 & 3907 & 10041 & 7.06 & 77 & 8.61 \\
\hline Granite & 2.61 & 5278 & 13776 & 6.48 & 89 & 14.23 \\
\hline
\end{tabular}

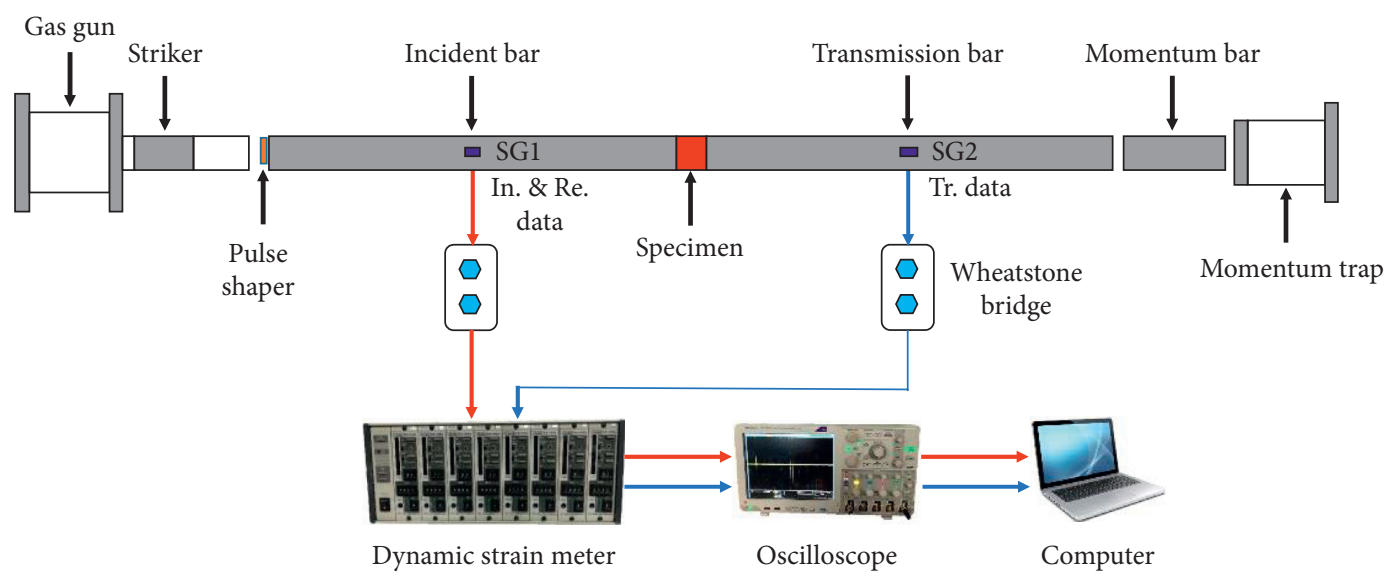

Figure 3: SHPB test system.

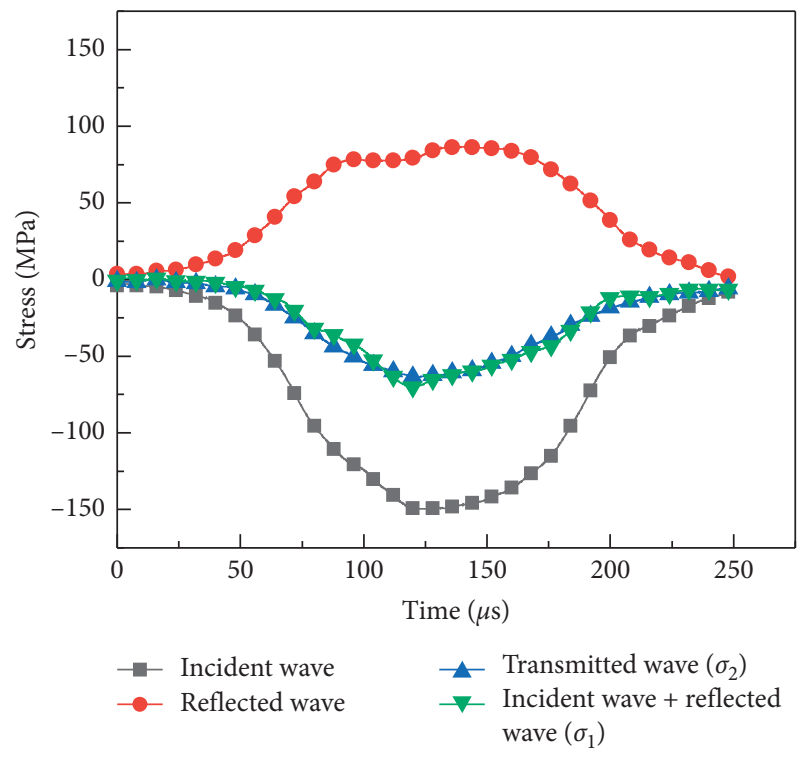

FIgURE 4: Verification of dynamic stress balance for typical specimen.

the impact loading process was basically the same. Therefore, the dynamic stress balance was well realized, and the stress-strain uniformity assumption of the sample was satisfied. The dynamic stress balance of each group of samples was verified during impact compression. Under the conditions that the one-dimensional stress wave assumption and uniformity assumption are satisfied, the strain rate $(\dot{\varepsilon})$, strain $(\varepsilon)$, and stress $(\sigma)$ of a sample can be calculated by

$$
\left.\begin{array}{l}
\dot{\varepsilon}=-\frac{2 C_{b}}{L_{0}} \varepsilon_{r} \\
\varepsilon=-\frac{2 C_{b}}{L_{0}} \int_{0}^{t} \varepsilon_{r} \mathrm{~d} t \\
\sigma=\frac{A_{b} E_{b}}{A_{0}} \varepsilon_{t}
\end{array}\right\},
$$

where $C_{b}$ is the elastic wave velocity of the bar and $L_{0}$ is the length of the sample.

\section{Results and Analysis}

3.1. Stress Wave Propagation Characteristics. The impact speed of each group of compression tests was controlled between 6-12 m/s. The incident, reflected, and transmitted waves of the three rock types in the range of test impact velocity were compared and analyzed, as shown in Figure 5. It was found that the incident, reflected, and transmitted waves of all three rock types increased with the increase of impact velocity. At the same impact velocity, the incident waves of the three kinds of rock were basically the same, and the reflected and transmitted waves showed significant differences. The sizes of the reflected waves were ordered as follows: red sandstone $>$ gray sandstone $>$ granite.

Wang [36] theoretically studied the reflection and transmission of elastic waves at the interface between two mediums when the elastic waves propagate from one wave impedance medium to another. The relationship between 


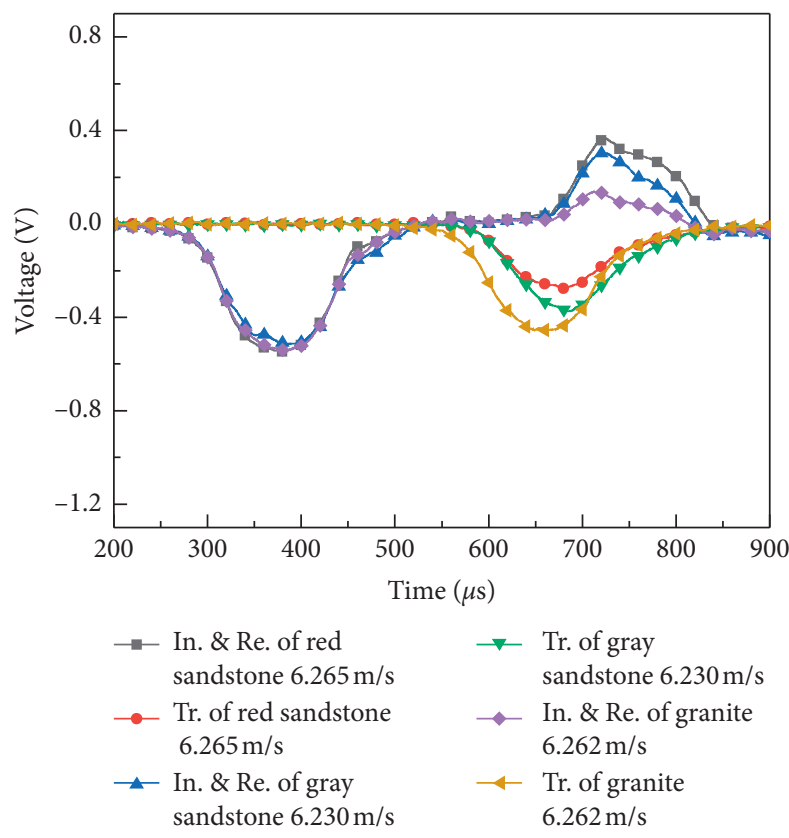

(a)

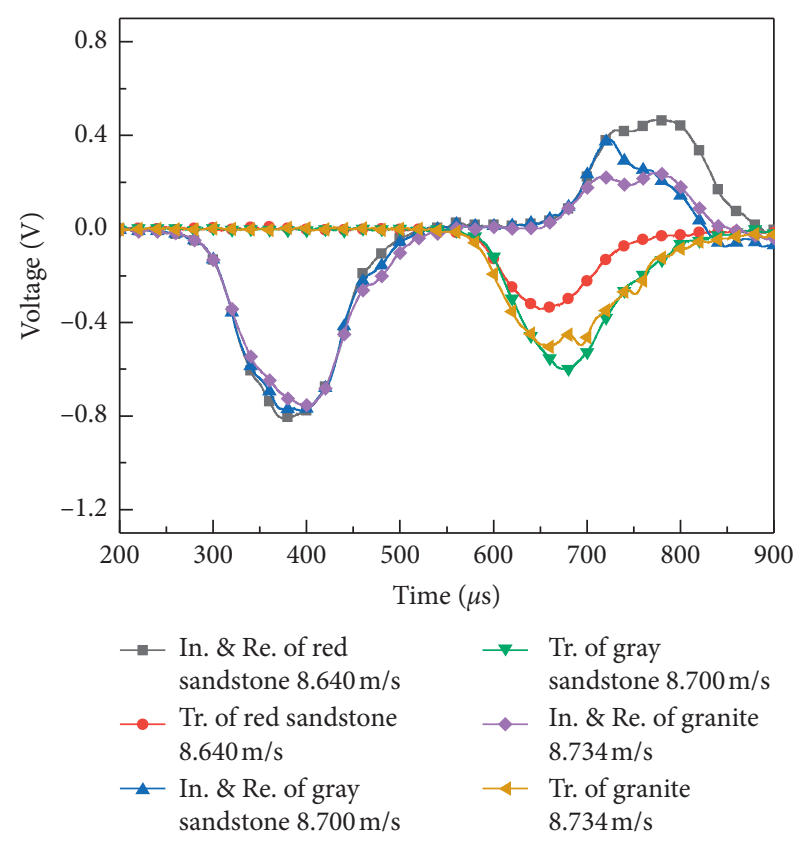

(c)
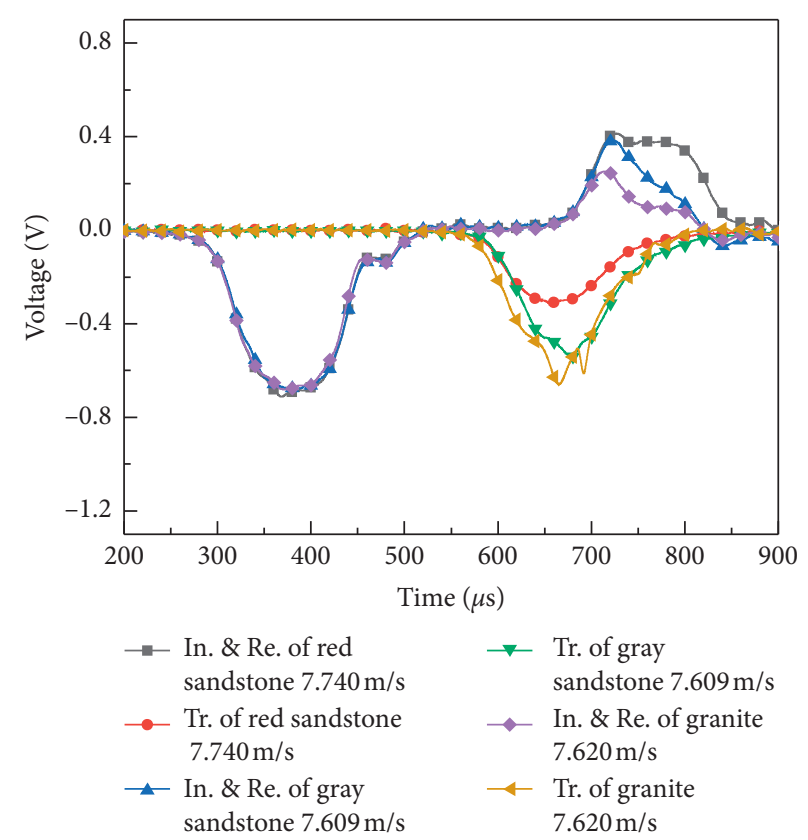

(b)

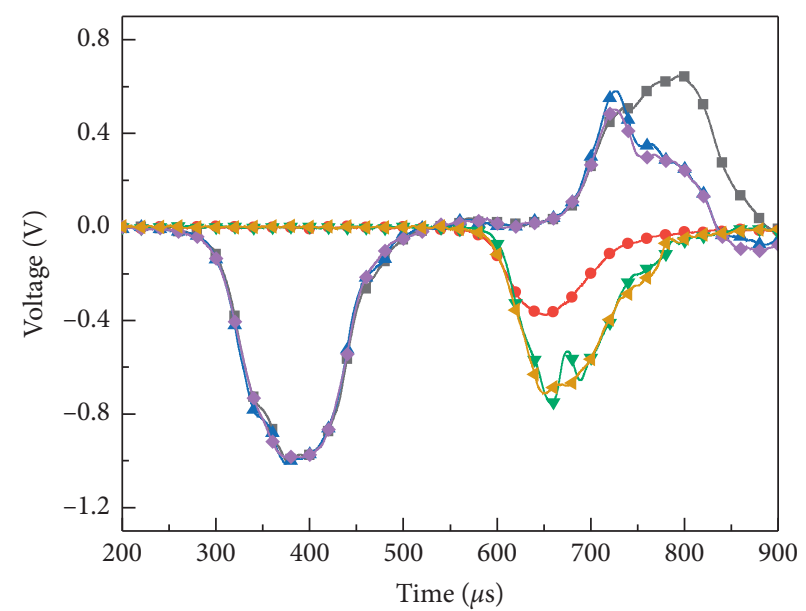

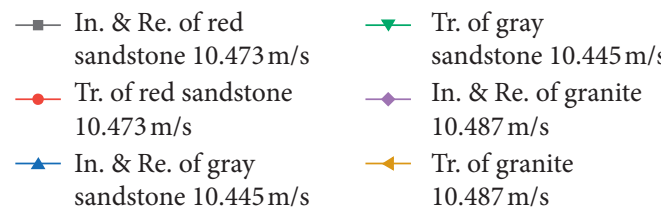

(d)

FIGURE 5: Waveform comparison chart of three kinds of rocks: (a) $6.25 \mathrm{~m} / \mathrm{s}$, (b) $7.65 \mathrm{~m} / \mathrm{s}$, (c) $8.70 \mathrm{~m} / \mathrm{s}$, and (d) $10.45 \mathrm{~m} / \mathrm{s}$.

the reflection coefficient, transmission coefficient, and wave impedance ratio was also given, as shown in formula (3). However, it is worth noting that equation (3) is derived for the consolidation interface (which can withstand tensile and compressive stresses without separation) based on continuous conditions and Newtonian theory. This is different from the reflection and transmission of waves at the interface (which can only withstand compressive stress without separation) between the incident bar and the rock sample in the SHPB test. Therefore, the calculation of the reflection coefficient cannot be performed according to formula (3) in the SHPB test. However, it is not difficult to determine from equation (3) that in the SHPB impact compression test, a higher the degree of wave impedance matching between the rock sample and the bar is associated with less wave reflection. The relationship is expressed as 


$$
\left.\begin{array}{l}
n=\frac{\left(\rho_{0} c_{0}\right)_{1}}{\left(\rho_{0} c_{0}\right)_{2}} \\
F=\frac{(1-n)}{(1+n)} \\
T=\frac{2}{(1+n)}
\end{array}\right\},
$$

where $\left(\rho_{0} c_{0}\right)_{1}$ and $\left(\rho_{0} c_{0}\right)_{2}$ are the wave impedances of the two media, $n$ is the wave impedance ratio of the two media, $F$ is the reflection coefficient, and $T$ is the transmission coefficient.

The results show that the magnitude relationship between the reflected waves of the three kinds of rock under the same impact velocity is related to the matching degree of wave impedance between the rock and bar. Table 1 shows that in terms of wave impedance, red sandstone < gray sandstone < granite; therefore, the matching degree of wave impedance between the granite sample and the incident steel bar was the highest, followed by that of the gray sandstone, and the matching degree of the red sandstone was the lowest. When the incident wave propagates through the incident bar to the incident bar-sample interface, a higher matching degree of wave impedance is associated with less wave reflection. Therefore, under the same impact velocity, in terms of reflected waves, red sandstone $>$ gray sandstone $>$ granite .

3.2. Dynamic Stress-Strain Relationship. The stress-strain curves of the three kinds of rock under different impact speeds are shown in Figure 6. These relationships all show obvious strain rate effects: the dynamic elastic modulus, peak stress, and peak strain of the rock samples increased with the increase of impact velocity, and the dynamic uniaxial compressive strength and dynamic elastic modulus were improved to varying degrees compared with static parameters. Regarding the range of test impact speeds, comparative study of the stress-strain curves of three kinds of rock was conducted and found that the red sandstone had the highest peak strain and the largest range of peak strain, followed by the gray sandstone; the granite had the smallest peak strain and the smallest range of peak strain. The peak stress of the red sandstone was small, and the peak stress changed less with the impact velocity. The peak stresses of the gray sandstone and granite were larger, and the peak stress varied significantly with the impact velocity. The red sandstone had the smallest dynamic elastic modulus, ranging from 5.9 to 9.2 GPa. The gray sandstone was in the middle, with a dynamic elastic modulus distribution range of 8.5-14.9 GPa. The dynamic elastic modulus of the granite was the largest, between 14.0 and $32.6 \mathrm{GPa}$. In terms of the unloading section, that of the red sandstone was gentle. However, the stress of the gray sandstone and granite decreased rapidly with the increase of strain when the stress reached the peak value, forming a steep unloading section. In conclusion, the stress-strain relationship of the red sandstone showed the characteristics of weak rock, its dynamic uniaxial compressive strength was low, and its brittleness was slight. However, the granite showed the characteristics of hard rocks, its dynamic uniaxial compressive strength was large, and its brittleness was apparent.

The relationships between impact velocity, strain rate, and peak stress for the three kinds of rock were compared and analyzed. The strain rate-impact velocity, peak stress-impact velocity, and peak stress-strain rate relationships of three kinds of rock are plotted, respectively, in Figures 7-9. Figure 7 shows that there was a strong positive linear correlation between the strain rate and the impact velocity. Moreover, the red sandstone strain rate had the largest change with impact velocity, the gray sandstone strain rate had the smallest change, and the granite was in the middle. Therefore, within the same impact velocity range, in terms of the strain rate range, red sandstone $>$ granite $>$ gray sandstone. Under the same impact velocity, in terms of the strain rate, red sandstone $>$ gray sandstone $>$ granite. These results are consistent with the relationship between the reflected waves of the three kinds of rock at the same impact velocity, as described in Section 3.1. From equation (2), it can be seen that the strain rate of the rock sample in the SHPB impact compression test is calculated from the reflected wave; thus, the size relationship between the reflected waves can roughly reflect the size relationship between the strain rates. The difference between the strain rates of the three kinds of rock at the same impact velocity was a mechanical manifestation of the difference between reflected waves caused by the matching degree of wave impedance.

Figure 8 shows that the peak stress and impact velocity also showed a strong positive linear correlation. The peak stress of the red sandstone was small, and the amplitude of changes in peak stress with impact velocity was small. The peak stresses of the gray sandstone and granite were large and similar in size. Figure 9 shows that the peak stress of the three kinds of rock increased linearly with the increase of strain rate. At the same time, it was not difficult to determine that in terms of the sensitivity of the peak stress to the strain rate, gray sandstone $>$ granite $>$ red sandstone. As the strain rate ranges of the three kinds of rock were different in the same impact velocity range, only the cross sections (110-150 s $\mathrm{s}^{-1}$, area II in Figure 9) of the strain rate ranges of the three kinds of rock were compared and analyzed. At the same strain rate, the peak stress of the red sandstone was still much smaller than those of the gray sandstone and granite. The size relationship between the peak stress of the gray sandstone and granite was determined as follows: when the strain rate was within the range of $110-125 \mathrm{~s}^{-1}$, the peak stress of the gray sandstone was smaller than that of the granite; when the strain rate was within the range of $125-150 \mathrm{~s}^{-1}$, the peak stress of the gray sandstone was greater than that of the granite. 


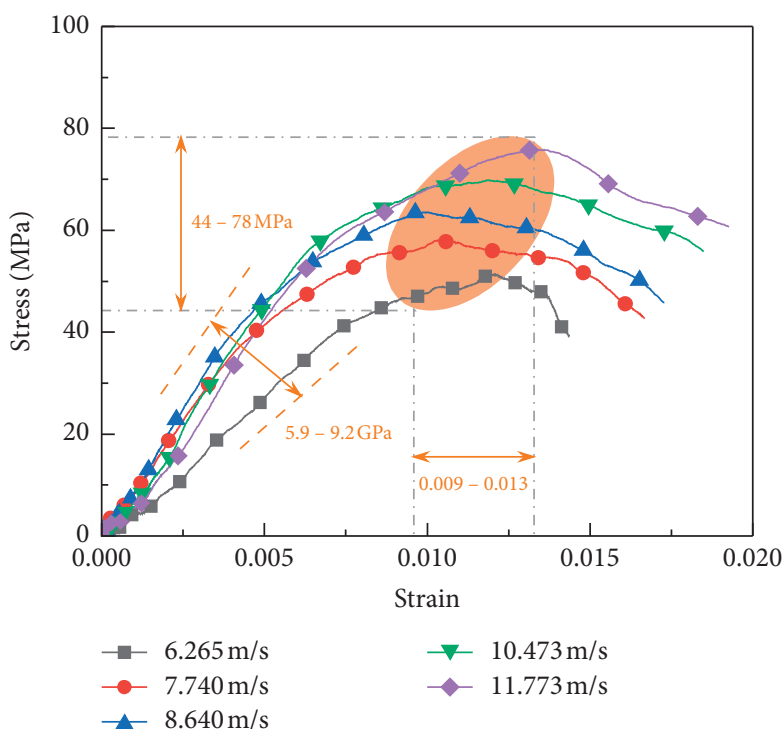

(a)

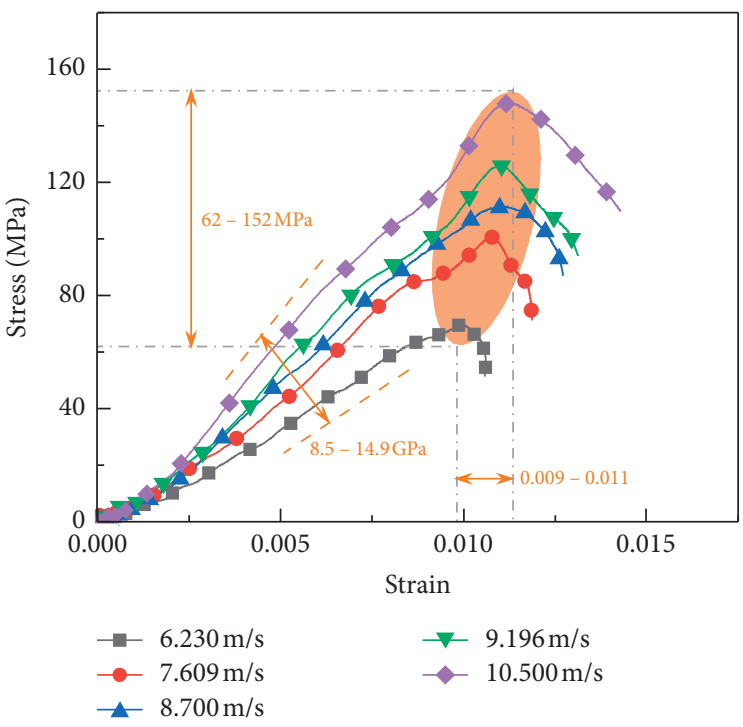

(b)

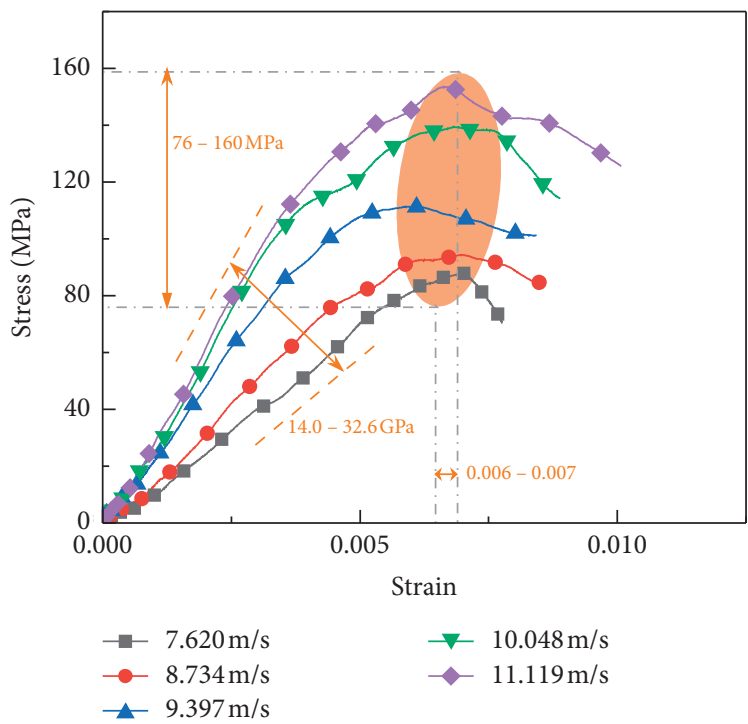

(c)

FIGURE 6: Stress-strain curve: (a) red sandstone, (b) gray sandstone, and (c) granite.

3.3. Energy Dissipation Analysis. When a Hopkinson pressure bar is used to perform a uniaxial impact compression test on a rock sample, the energy absorbed by the rock sample can be calculated by formula (4) based on the principle of energy conservation [21] and ignoring energy loss at the specimen-bar interface:

$$
W_{L}=W_{I}-\left(W_{R}+W_{T}\right)
$$

where $W_{I}, W_{R}$, and $W_{T}$ represent the energy of the incident wave, reflected wave, and transmitted wave, respectively.

According to the one-dimensional linear elastic stress wave theory, the energy of the incident wave, reflected wave, and transmitted wave can be calculated by the following formula $[21,23]$ :

$$
\left.\begin{array}{c}
W_{I}=\frac{A_{b} C_{b}}{E_{b}} \int_{0}^{t} \sigma_{i}^{2} \mathrm{~d} t \\
W_{R}=\frac{A_{b} C_{b}}{E_{b}} \int_{0}^{t} \sigma_{r}^{2} \mathrm{~d} t \\
W_{T}=\frac{A_{b} C_{b}}{E_{b}} \int_{0}^{t} \sigma_{t}^{2} \mathrm{~d} t
\end{array}\right\},
$$

where $\sigma_{i}, \sigma_{r}$, and $\sigma_{t}$ are the incident stress wave, reflected stress wave, and transmitted stress wave, respectively.

According to the research results of Zhang et al. [21], most of the energy absorbed by a rock sample is used through rock fracture and damage to generate new cracks and fracture surfaces, accounting for about $95 \%$ of the 


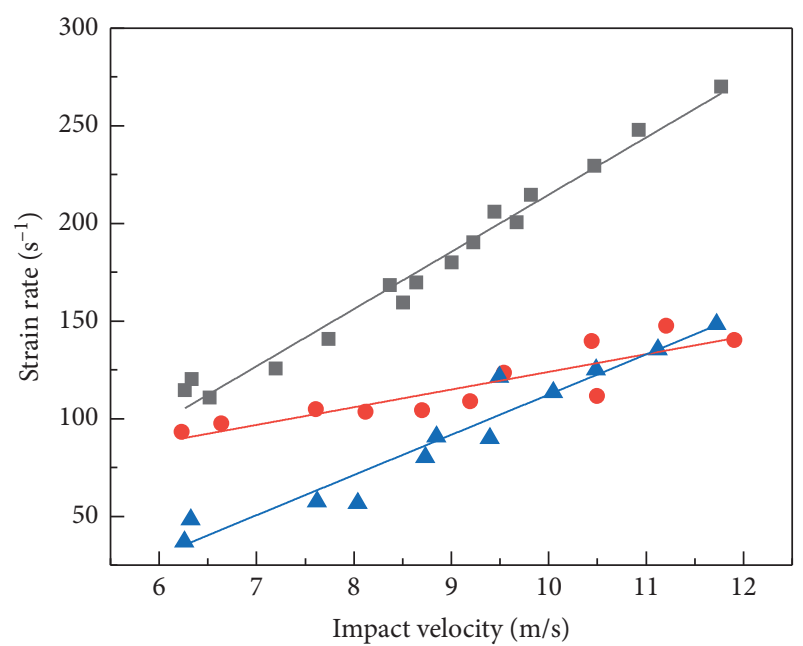

Data point Linear fit

$$
\begin{aligned}
& -\quad \text { Red sandstone } \\
& \text { Gray sandstone } \\
& \text { Granite }
\end{aligned}
$$

FIGURE 7: Strain rate-impact velocity diagram.

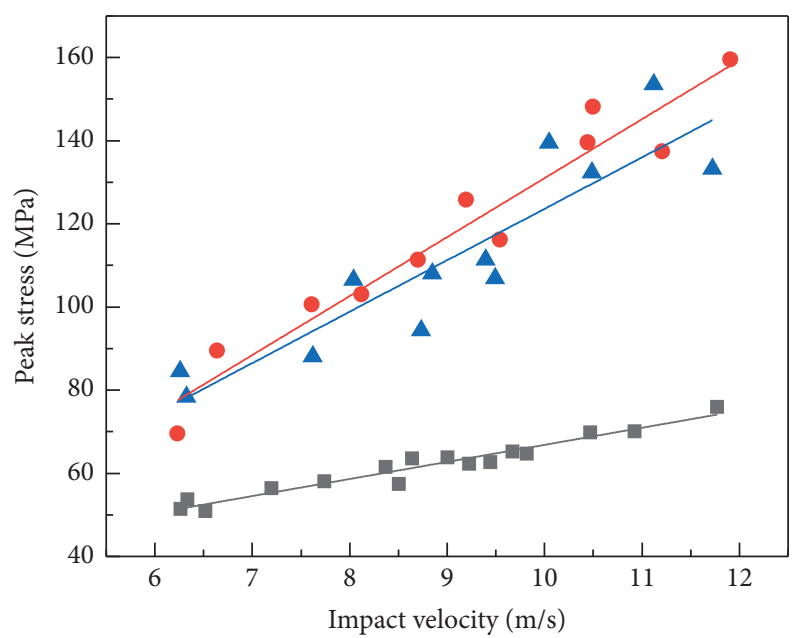

Data point Linear fit

$$
\begin{array}{ll}
-\quad-\quad & \text { Red sandstone } \\
\text { Gray sandstone } \\
\text { Granite }
\end{array}
$$

FIgURe 8: Peak stress-impact velocity diagram.

energy. The flying kinetic energy of rock fragments and other forms of energy consumption account for only about $5 \%$ of the absorbed energy. Therefore, it is assumed in this study that the dissipation energy $\left(W_{d}\right)$ of the rock sample is approximately equal to the energy absorbed by the sample; that is, $W_{d} \approx W_{L}$. The dissipated energy per unit volume of rock is represented by the energy dissipation density $\left(\omega_{d}\right)$, which can be calculated using the following formula:

$$
\omega_{d}=\frac{W_{d}}{V} \approx \frac{W_{L}}{V},
$$

where $V$ is the volume of the rock sample.

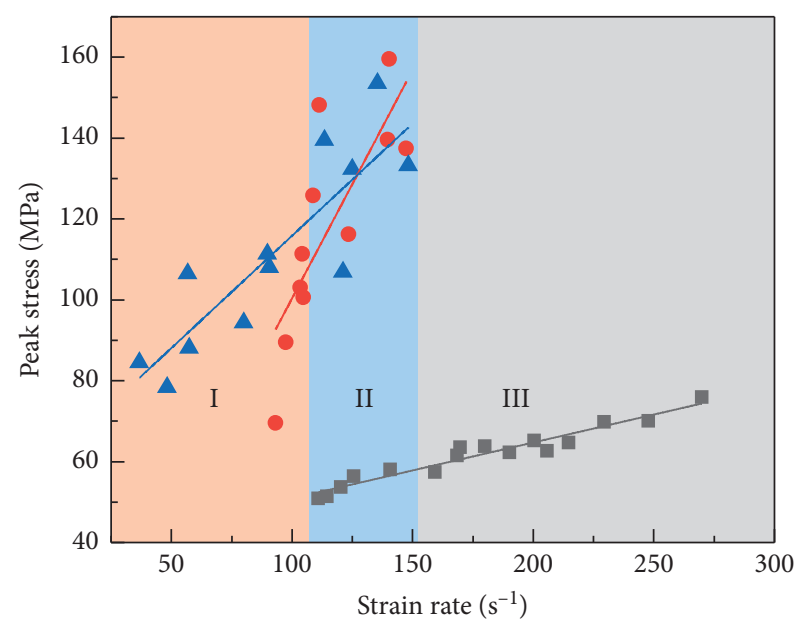

$\begin{array}{cll}\text { Data point Linear fit } & \\ - & - & \text { Red sandstone } \\ - & - & \text { Gray sandstone } \\ & - & \text { Granite }\end{array}$

Figure 9: Peak stress-strain rate diagram.

According to equations (4)-(6), the incident energy, reflection energy, transmission energy, dissipated energy, and energy dissipation density of the three kinds of rock at various impact velocities were calculated. Comparisons of the impact speed, strain rate, incident energy, reflected energy, and energy dissipation density of the three kinds of rock are shown in Figures 10-13. Figures 10 and 11 show that the magnitude of incident energy was independent of the rock sample and had a strong positive linear correlation with the impact velocity. The reflection energy of all three kinds of rock increased linearly with the increase of incident energy. The size relationship of the reflection energy between the three kinds of rock was as follows: red sandstone $>$ gray sandstone $>$ granite. In addition, the reflection energy of the red sandstone changed more strongly than that of the gray sandstone and granite with the incident energy; thus, the gap between the reflection energy of the red sandstone and the reflection energy of the gray sandstone and granite increased with the increase of incident energy. This finding is consistent with the size relationship between the reflected waves and strain rates of the three kinds of rock at the same impact velocity, as mentioned in Sections 3.1 and 3.2. From equation (5), it can be seen that the reflection energy of the rock sample in the SHPB impact compression test is calculated from the reflected wave; thus, the size relationship between the reflected waves can reflect the size relationship between the reflected energy. The difference in reflection energy of the three kinds of rock under the same incident energy was an energy manifestation of the difference between reflected waves caused by the matching degree of wave impedance.

Within the range of the test impact speed, the energy dissipation densities of the three kinds of rock were basically between 0.2 and $2.0 \mathrm{~J} / \mathrm{cm}^{3}$ and increased linearly with the increase of the strain rate. In terms of the sensitivity of energy dissipation density to strain rate, gray 


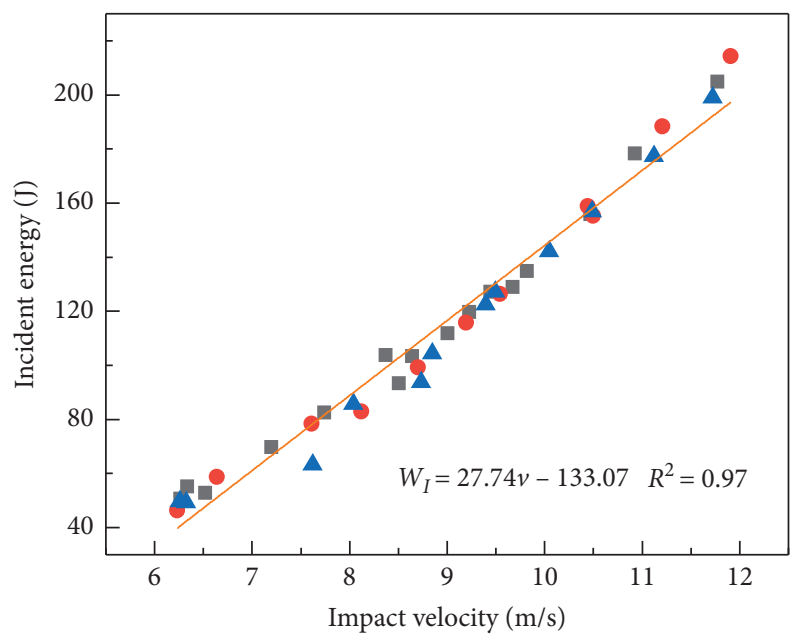

- Red sandstone

- Gray sandstone

Granite

FIGURE 10: Incident energy-impact velocity diagram.

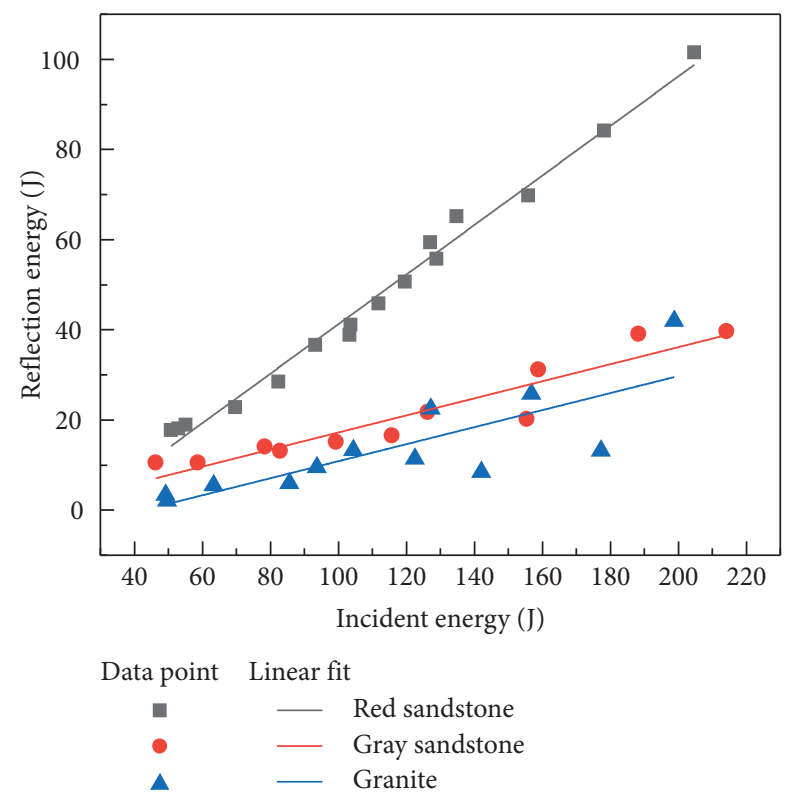

FIGURE 11: Reflection energy-incident energy diagram.

sandstone $>$ granite $>$ red sandstone, as shown in Figure 12 . In addition, because the strain rate ranges of the three kinds of rock were different within the same impact velocity range, comparative analysis of the energy dissipation density was performed only at the intersection of the strain rate ranges of the three kinds of rock (110-150 s ${ }^{-1}$, area II in Figure 12). At the same strain rate, the energy dissipation density of the red sandstone was smaller than those of the gray sandstone and granite. The size relationship between the energy dissipation density of the gray sandstone and granite was as follows: when the strain rate was within the range of $110-125 \mathrm{~s}^{-1}$, the energy dissipation density of the gray sandstone was smaller than that of the granite; when the strain rate was within the

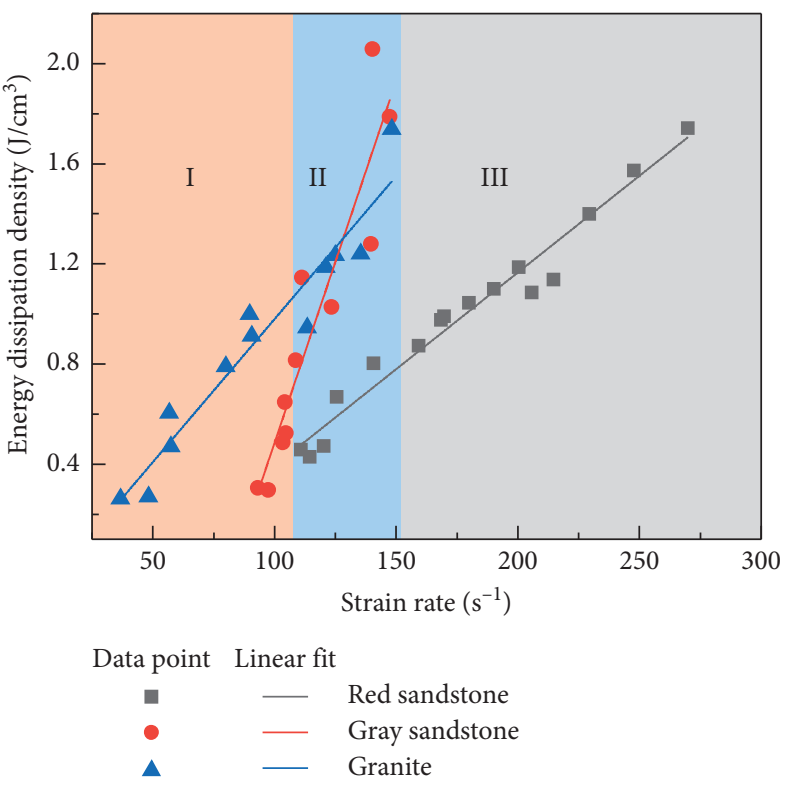

FIGURE 12: Energy dissipation density-strain rate diagram.

range of $125-150 \mathrm{~s}^{-1}$, the energy dissipation density of the gray sandstone was greater than that of the granite.

Figure 13 shows that the energy dissipation densities of the three kinds of rock increased linearly with the increase of incident energy. In addition, the three kinds of rock had different amplitudes of change in energy dissipation density with incident energy. The magnitude of change in energy dissipation density with incident energy was greater for the gray sandstone than for the red sandstone and granite. Therefore, under the same incident energy, the energy dissipation density of the three kinds of rock showed different size relationships at different incident energy intervals. When the incident energy was low (test conditions: 40-120 J, area I in Figure 13), in terms of the energy dissipation density, red sandstone $>$ granite $>$ gray sandstone. When the incident energy was at an intermediate level (120-180 J, area II), red sandstone > gray sandstone $>$ granite, in terms of energy dissipation energy. When the incident energy was high (180-220 J, area III), for the energy dissipation density, gray sandstone $>$ red sandstone $>$ granite. Furthermore, in the range of the test incident energy, when the incident energy was the same, there were only small differences in the energy dissipation densities of the three kinds of rock.

The ratio of the dissipated energy to incident energy can characterize the efficiency of energy utilization. Therefore, the dissipated energy/incident energy-incident energy relationships of the three kinds of rock were plotted, as shown in Figure 14. Comparative analysis was performed on the relationship between the energy utilization efficiency of the three kinds of rock and incident energy. The figure shows that within the range of the incident energy of the test, the overall energy utilization efficiency of the red sandstone was high, and the energy utilization efficiency varied little with the incident energy; energy utilization efficiency was between $40 \%$ and $50 \%$. The energy utilization efficiency of the 


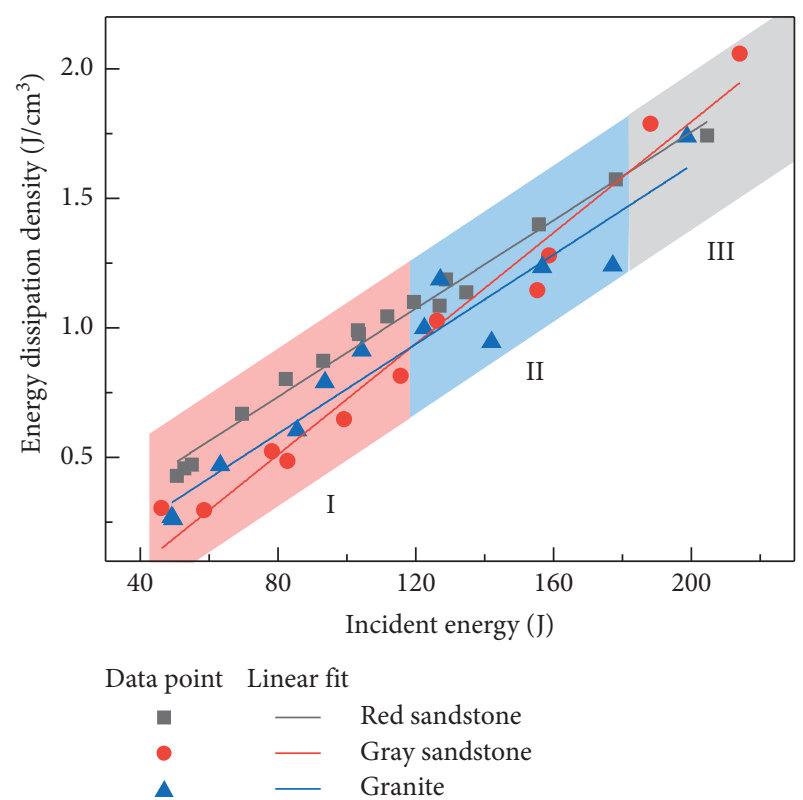

FIGURE 13: Energy dissipation density-incident energy diagram.

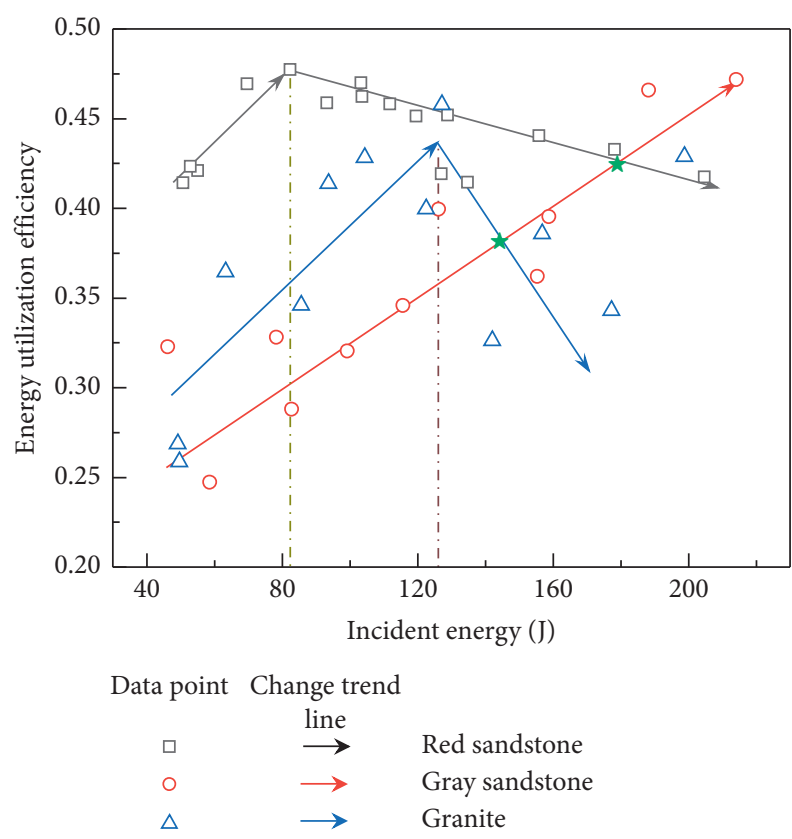

FIGURE 14: Energy utilization efficiency-incident energy diagram.

gray sandstone and granite varied greatly with the incident energy, and energy utilization efficiency was between $25 \%$ and $50 \%$. The trends of the energy utilization efficiency of the red sandstone and granite with incident energy were as follows: the energy utilization efficiency first increased with the increase of incident energy and then decreased with the increase of incident energy after the peak was reached. The red sandstone reached its peak energy utilization efficiency (about $48 \%$ ) when the incident energy was about $80 \mathrm{~J}$. The granite reached its peak energy utilization efficiency (about $48 \%$ ) at an incident energy of about $125 \mathrm{~J}$. The change trend of the energy utilization efficiency of the gray sandstone with incident energy was significantly different from those of the red sandstone and granite. There was no obvious extreme point in the incident energy range of the test. The energy utilization efficiency monotonically increased with the increase of incident energy and reached a peak of about $48 \%$ when the incident energy was about $210 \mathrm{~J}$. Therefore, the size relationship between the energy utilization efficiency of the three kinds of rock can be roughly divided into three parts: when the incident energy was low (approximately 40-140 J), red sandstone $>$ granite $>$ gray sandstone; when the incident energy was at a middle level (140-180 J), red sandstone > gray sandstone $>$ granite; when the incident energy was high (180-220 J), gray sandstone $>$ red sandstone $>$ granite.

3.4. Rock Fragmentation. The equivalent average size $\left(d_{m}\right)$ of rock fragments can directly and quantitatively describe the degree of fragmentation of rock samples after impact compression, and $d_{m}$ can be calculated as follows [20]:

$$
d_{m}=\frac{\sum\left(\omega_{i} \bar{d}_{i}\right)}{\sum \omega_{i}}
$$

where $\bar{d}_{i}$ is the mean size of fragments situated between sieves with successive mesh sizes (the average of two continuous sieve sizes was taken in this study), and $\omega_{i}$ is the mass fraction of fragments corresponding to the size of $\bar{d}_{i}$.

After the SHPB impact compression test, three kinds of rock sample fragments were collected and then sieved. Standard sieves with a total of 14 hole sizes, 37.5, 31.5, 26.5, $19,16,13.2,9.5,4.75,2.36,1.18,0.6,0.3,0.15$, and $0.075 \mathrm{~mm}$, were adopted. Taking the impact compression test of the gray sandstone at an impact speed of $11.208 \mathrm{~m} / \mathrm{s}$ as an example, the block distribution of the fragments is shown in Figure 15. According to formula (7), the equivalent average size $\left(d_{m}\right)$ of the fragments was $14.18 \mathrm{~mm}$.

The degrees of fragmentation of the three kinds of rock after the SHPB impact compression test were compared and analyzed. Fragments of the three kinds of rock produced by impact velocities within the range of $7-12 \mathrm{~m} / \mathrm{s}$ are shown in Figure 16. Taking the impact velocity of $9.5 \mathrm{~m} / \mathrm{s}$ as an example, the block distributions of the three kinds of rock fragments at the same impact velocity were compared, as shown in Figure 17. The distribution rules of the three kinds of rock fragments at other impact velocities were similar and will not be described separately. Rock failure can be viewed as a state instability phenomenon driven by energy. Energy dissipation is the root cause of rock deformation and failure. Therefore, it was necessary to couple the dissipation energy to compare and analyze the fracture degrees of the three kinds of rock. Thus, the equivalent average size-impact velocity-energy dissipation density relationship of the three kinds of rock was plotted, as shown in Figure 18.

Figures 16-18(b) show that when the impact velocity was low, the damage degree of the three kinds of rock was low, with more large blocks, fewer small blocks, or almost no small blocks. With the increase of the impact velocity, the damage degree of the three kinds of rock increased, the 


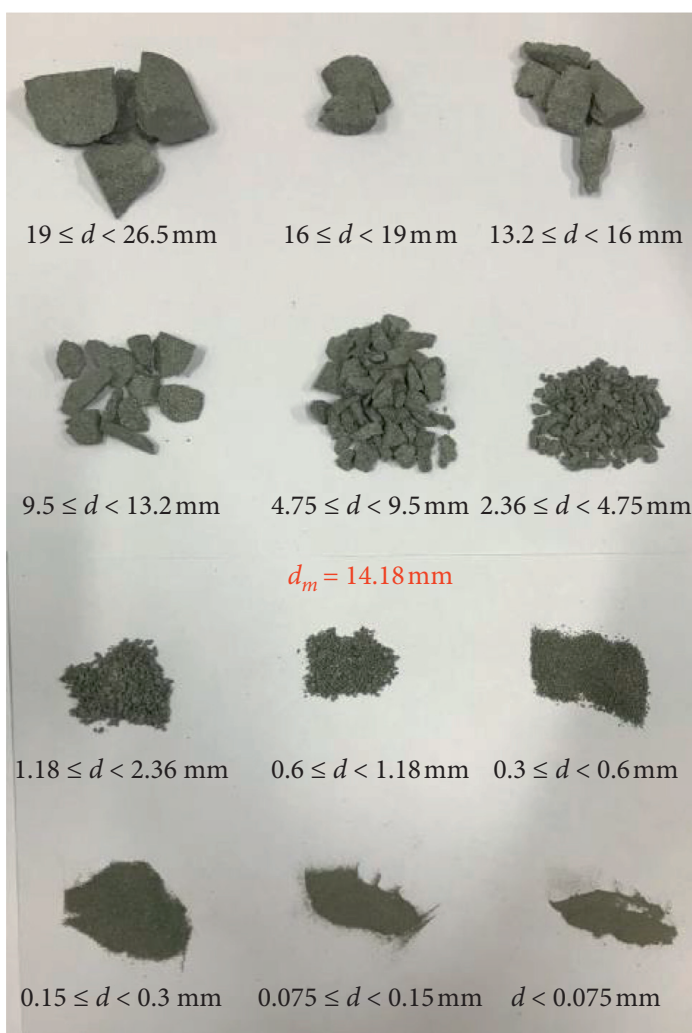

(a)

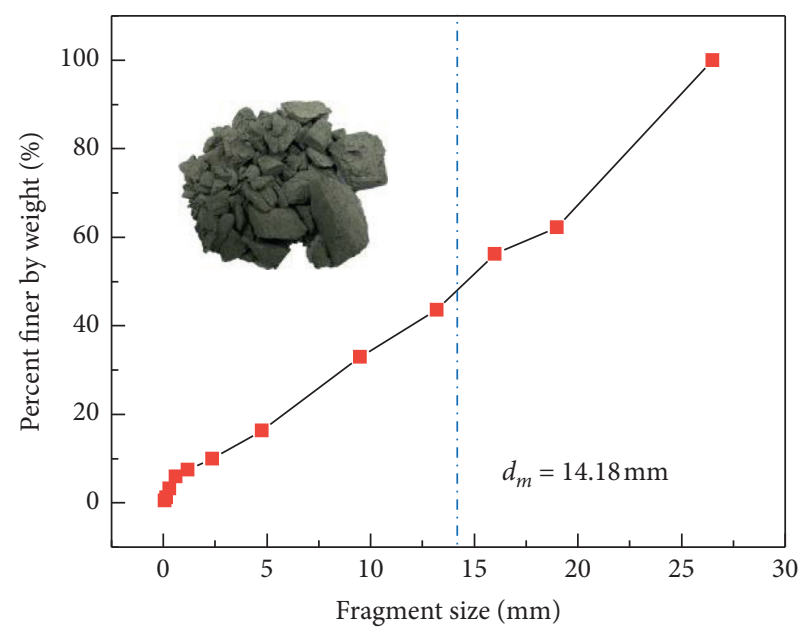

$\rightarrow$ Percent finer by weight

(b)

FIGURE 15: Fragment distribution of gray sandstone at an impact speed of $11.208 \mathrm{~m} / \mathrm{s}$ : (a) fragments with various sizes and (b) fragment size distribution.

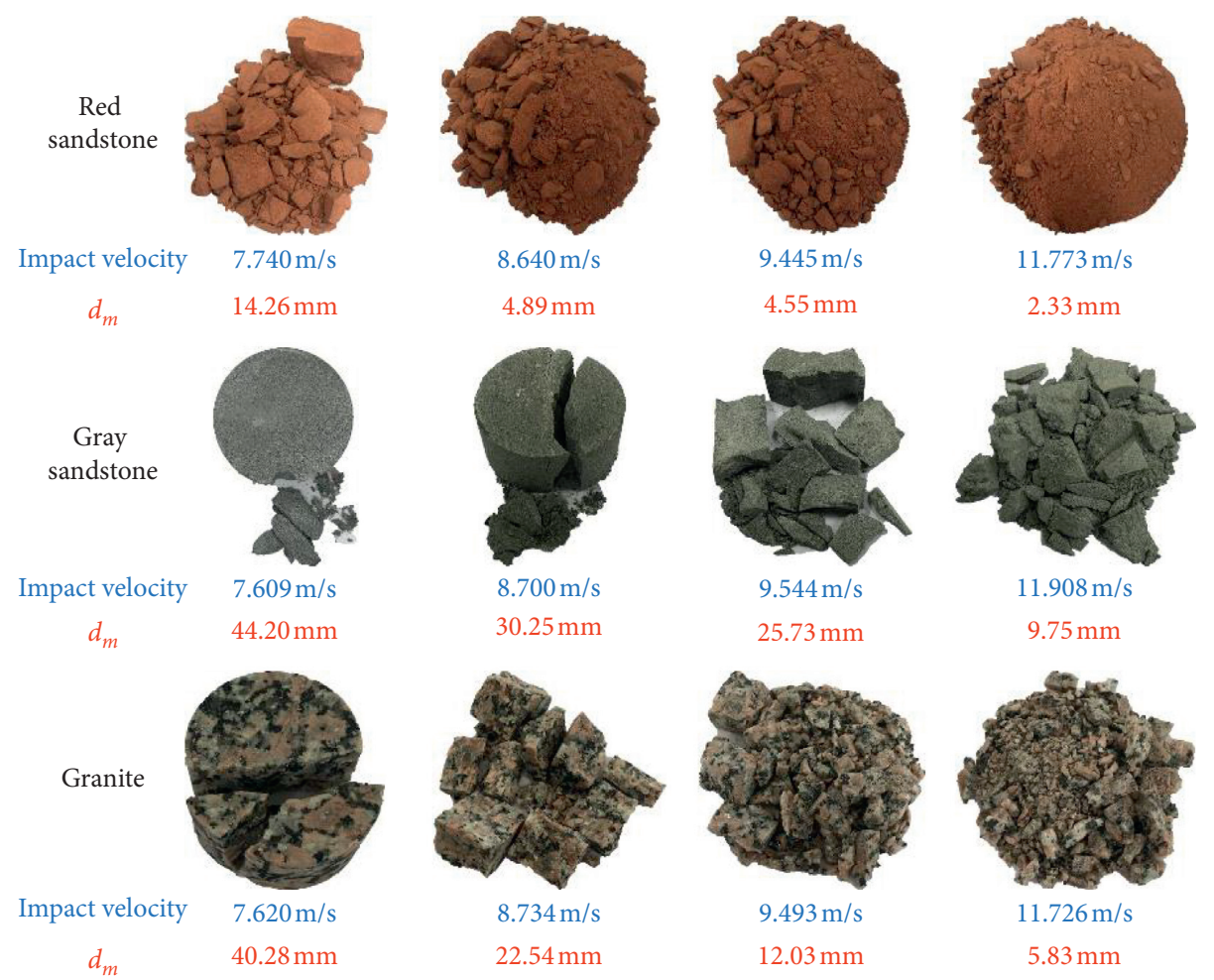

Figure 16: Comparison of fragments of three kinds of rocks. 


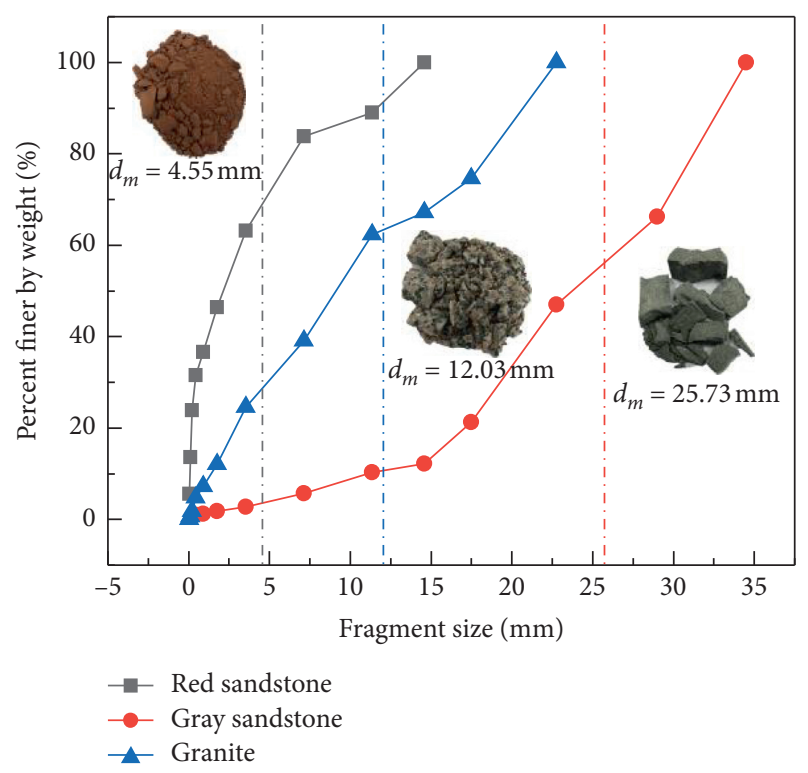

FIGURE 17: Comparison of fragment distributions at an impact speed of $9.5 \mathrm{~m} / \mathrm{s}$.

number of large blocks of rock fragments continued to decrease, and the number of small blocks continued to increase. When the impact velocity reached about $12 \mathrm{~m} / \mathrm{s}$, there either were fewer large blocks or almost no large blocks. The equivalent average sizes of the three kinds of rock fragments decreased as a function of power as the impact velocity increased. Within the test impact speed range, at the same impact speed, the damage degree of the red sandstone was the most severe, and the equivalent average size of the fragments was the smallest. The granite had the second greatest damage degree and the second smallest equivalent average fragment size. The damage degree of the gray sandstone was the smallest, and the equivalent average size of the fragments was the largest.

Figures 18(a) and 18(c) show that the equivalent average sizes of the three kinds of rock fragments decreased as a function of power as the energy dissipation density increased; that is, the damage degree of the three kinds of rock increased with the increase of the energy dissipation density. In the range of test impact speed, under the same energy dissipation density, the equivalent average size of the red sandstone fragments was the smallest, and the degree of damage was the most severe. The granite had the second smallest equivalent average fragment size, and the degree of damage was in the middle. The equivalent average size of the gray sandstone fragments was the largest, and the degree of damage was the smallest. These results show the difference in the degree of damage when the three kinds of rock absorbed the same amount of energy. In addition, Figure 18(c) shows that the three kinds of rock needed different amounts of energy to reach the same level of damage (that is, the same equivalent average fragment size). The gray sandstone required the most energy, followed by the granite, and the red sandstone required the least energy. Thus, the three kinds of rock had different levels of difficulty in achieving the same degree of damage. The red sandstone was the easiest to destroy, followed by the granite, and the gray sandstone was the most difficult to destroy.

\section{Discussion}

(1) Figure 5 shows that within the range of the test impact speed, under the same impact speed, the size relationship between the reflected waves of the three rock types is generally expressed as red sandstone $>$ gray sandstone $>$ granite. However, as the impact velocity increased, the gap between the reflected waves of the gray sandstone and granite tended to consistently decrease. The analysis showed that the SHPB impact compression test of rock samples is a dynamic loading process. Related research has shown that the samples will undergo compression and closure of microdefects such as microvoids and microcracks in the initial stage of loading [37-39]. Therefore, the stress-strain curve of a rock with multiple pores also shows an obvious compaction stage. The compression and closure of microdefects will inevitably change the density and P-wave velocity of the rock sample. Therefore, it can be predicted that the wave impedance of the rock sample will continuously change during the dynamic loading process. The porosity of the gray sandstone was higher than that of the granite; consequently, the changes of density and wave velocity during impact compression were more obvious, and the wave impedance of the gray sandstone changed more during dynamic loading. Therefore, the difference in wave impedance between the gray sandstone and granite during dynamic loading was smaller than that obtained by static measurement. Moreover, as the impact velocity increased, the compression and closure of microdefects became more sufficient, and the difference in wave impedance between the gray sandstone sample and the granite sample decreased during dynamic loading. When a certain impact speed is reached, the wave impedance can even reach an equal level or show little difference. Therefore, with the increase of impact velocity, the size difference between the reflected waves of the gray sandstone and granite continued to decrease and tended to be consistent. The red sandstone was affected by its own mineral composition; even if the microdefects were greatly compressed, the increases in wave velocity and density were very limited, and the reflected wave therefore was still large. Subsequent tests will evaluate how dynamic measurement of volume and wave velocity may be achieved during impact loading of rock samples, thereby verifying this analysis.

(2) Figures 13 and 16 show that under the same incident wave, the three kinds of rock showed different degrees of fragmentation, but the difference in dissipation energy was small. These findings show that different rocks of different lithologies require different amounts of energy to generate a unit fracture 


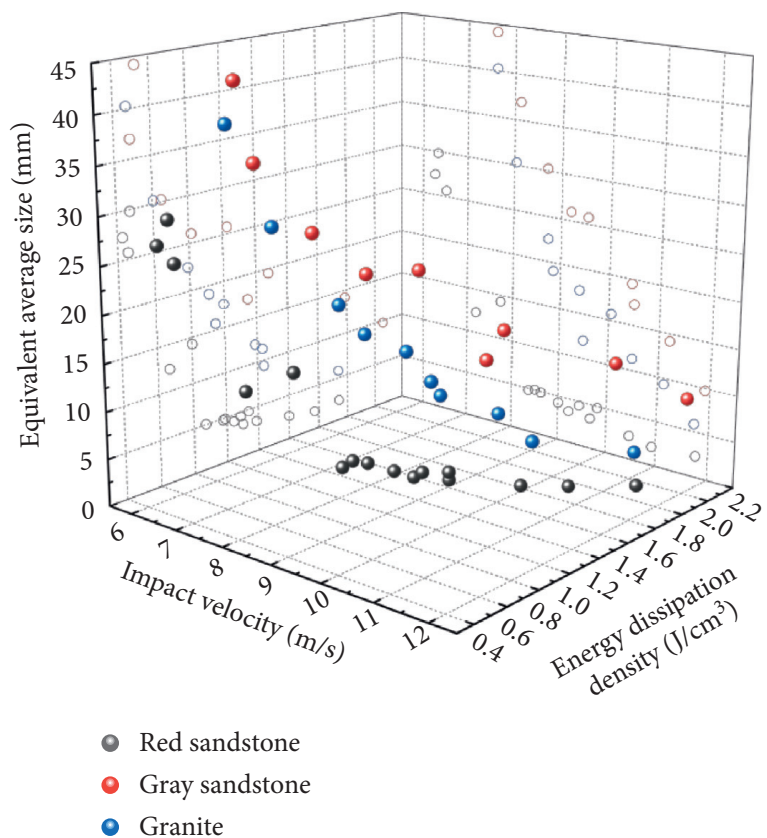

(a)

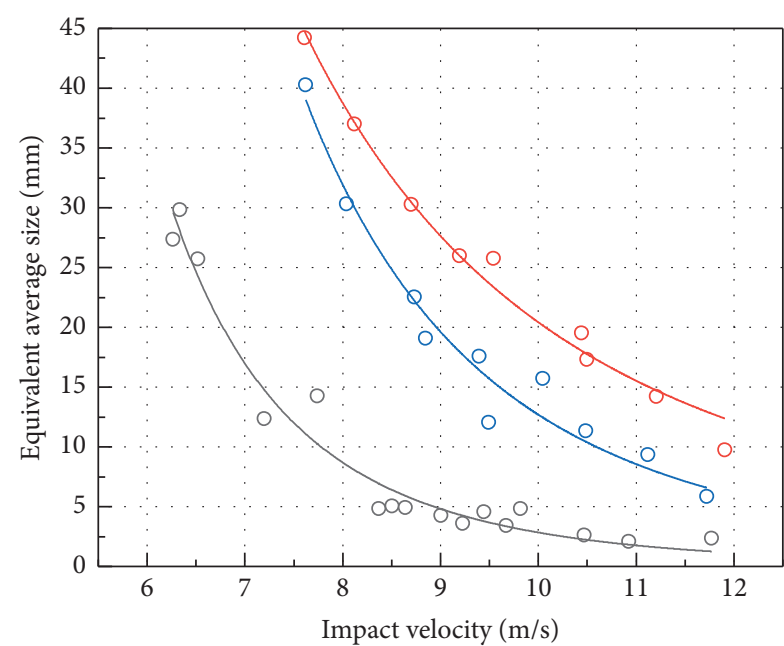

Data point Power function fitting

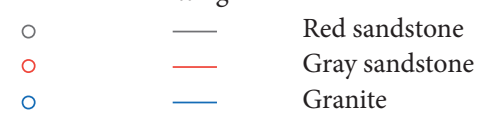

(b)

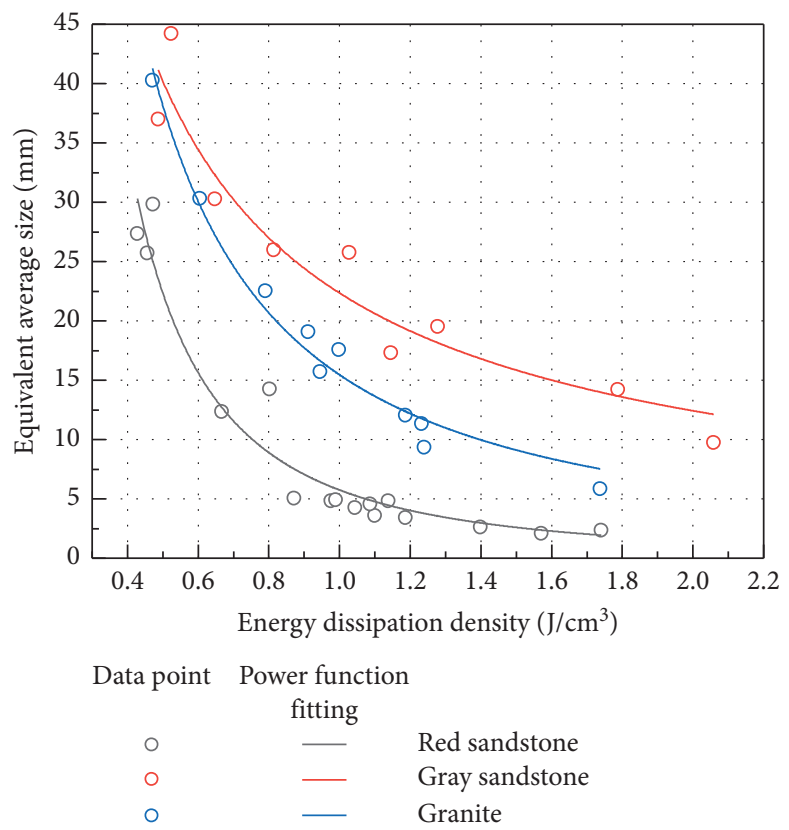

(c)

FIGURE 18: Equivalent average size-impact velocity-energy dissipation density diagram: (a) three dimensional diagram, (b) equivalent average size-impact velocity diagram, and (c) equivalent average size-energy dissipation density diagram.

surface, and the difficulty of destruction differs. However, for additional rock types, is there less difference between the dissipation energy of rocks under the same incident wave in a wider range of incident energy? This inference remains to be verified by comparative studies of rocks with different lithologies over a wider range of impact velocities.

(3) Figure 14 shows that the change trend of the energy utilization efficiency of the gray sandstone with incident energy was significantly different from those of the red sandstone and granite, and no obvious turning point or extreme point appeared in the range of incident energy of the test. Whether the energy utilization efficiency of gray sandstone will also undergo a similar turn under higher incident energy needs to be determined by impact compression testing at a higher impact speed. Thus, the general law of energy utilization efficiency of rocks of different lithologies changing with incident energy remains to be further explored. 


\section{Conclusions}

(1) Under the same incident stress wave, three kinds of rock with different wave impedance had different reflected waves, strain rates, and reflected energy. The strain rate and reflected energy are the mechanical and energy manifestations of the reflected wave; thus, the size relationship between the strain rate and the reflected energy of the three kinds of rock was consistent with the size relationship between the reflected waves. Affected by the matching degree of wave impedance between the rock samples and the incident bar, in terms of the reflected wave, strain rate, and reflected energy, red sandstone $>$ gray sandstone $>$ granite.

(2) The dynamic stress-strain relationship and energy dissipation laws of the three kinds of rock showed obvious strain rate effects. The peak stress and energy dissipation density of the three kinds of rock increased linearly with the increase of strain rate. In terms of the sensitivity of peak stress and energy dissipation density to strain rate, gray sandstone $>$ granite $>$ red sandstone.

(3) Under the same incident energy, the differences between the energy dissipation densities of the three kinds of rock were small.

(4) Within the range of incident energy of the test, the overall energy utilization efficiency of the red sandstone was high, and the amplitude of change with incident energy was small. The energy utilization efficiency of the red sandstone and granite first increased and then decreases with the increase of incident energy. However, the energy utilization efficiency of the gray sandstone monotonously increased with the increase of incident energy, and no obvious turning point appeared. In terms of the incident energy required to reach the maximum energy utilization efficiency, red sandstone $<$ granite $<$ gray sandstone.

(5) The damage degree of the three kinds of rock increased with the increase of impact velocity and energy dissipation density. The equivalent average size of the fragments decreased as a function of power with the increase of impact velocity and energy dissipation density. Under the same impact velocity or the same energy dissipation density, in terms of the damage degree, red sandstone $>$ granite $>$ gray sandstone.

\section{Data Availability}

The data used to support the findings of this study are available from the corresponding author upon request.

\section{Conflicts of Interest}

The authors declare that they have no conflicts of interest.

\section{Authors' Contributions}

Renshu Yang was responsible for the study design, data analysis/interpretation, and statistical analysis. Weiyu Li was the guarantor of integrity of the entire study and was responsible for experimental studies, data acquisition, manuscript preparation, manuscript editing, manuscript revision/review, and other remaining contributions. Zhongwen Yue was responsible for the study concepts and literature research.

\section{Acknowledgments}

This research was supported by the State Key Development Program for Basic Research of China (no. 2016YFC0600903) and Institutions of Higher College Discipline Innovation Plan "111 Project” of China (no. B14006).

\section{References}

[1] C. Wu and H. Hao, "Modeling of simultaneous ground shock and airblast pressure on nearby structures from surface explosions," International Journal of Impact Engineering, vol. 31, no. 6, pp. 699-717, 2005.

[2] O. Tavasoli and M. Ghazavi, "Wave propagation and ground vibrations due to non-uniform cross-sections piles driving," Computers and Geotechnics, vol. 104, pp. 13-21, 2018.

[3] H. Hao, C. Wu, and Y. Zhou, "Numerical analysis of blastinduced stress waves in a rock mass with anisotropic continuum damage models part 1: equivalent material property approach," Rock Mechanics and Rock Engineering, vol. 35, no. 2, pp. 79-94, 2002.

[4] O. Tavasoli and M. Ghazavi, "Driving behavior of stepped and tapered offshore piles due to hammer blows," Marine Georesources \& Geotechnology, vol. 38, no. 6, pp. 633-646, 2020.

[5] L.-J. Dong, J. Wesseloo, Y. Potvin, and X.-B. Li, "Discriminant models of blasts and seismic events in mine seismology," International Journal of Rock Mechanics and Mining Sciences, vol. 86, pp. 282-291, 2016.

[6] O. Tavasoli and M. Ghazavi, "Effect of tapered and semitapered geometry on the offshore piles driving performance," Ocean Engineering, vol. 201, Article ID 107147, 2020.

[7] A. Ansell, "Laboratory testing of a new type of energy absorbing rock bolt," Tunnelling and Underground Space Technology, vol. 20, no. 4, pp. 291-300, 2005.

[8] L. F. Fan and H. Y. Sun, "Seismic wave propagation through an in-situ stressed rock mass," Journal of Applied Geophysics, vol. 121, pp. 13-20, 2015.

[9] J. C. Li, N. N. Li, S. B. Chai, and H. B. Li, "Analytical study of ground motion caused by seismic wave propagation across faulted rock masses," International Journal for Numerical and Analytical Methods in Geomechanics, vol. 42, no. 1, pp. 95109, 2018.

[10] Z. Zhou, X. Li, Z. Ye, and K. Liu, "Obtaining constitutive relationship for rate-dependent rock in SHPB tests," Rock Mechanics and Rock Engineering, vol. 43, no. 6, pp. 697-706, 2010.

[11] S. Liu and J. Xu, "Effect of strain rate on the dynamic compressive mechanical behaviors of rock material subjected to high temperatures," Mechanics of Materials, vol. 82, pp. 28-38, 2015. 
[12] Q. B. Zhang and J. Zhao, "A review of dynamic experimental techniques and mechanical behaviour of rock materials," Rock Mechanics and Rock Engineering, vol. 47, no. 4, pp. 1411-1478, 2014.

[13] J. Zhao, "Applicability of Mohr-Coulomb and Hoek-Brown strength criteria to the dynamic strength of brittle rock," International Journal of Rock Mechanics and Mining Sciences, vol. 37, no. 7, pp. 1115-1121, 2000.

[14] W. Wang, H. Wang, D. Li, H. Li, and Z. Liu, "Strength and failure characteristics of natural and water-saturated coal specimens under static and dynamic loads," Shock and Vibration, vol. 2018, no. 2, 15 pages, Article ID 3526121, 2018.

[15] B. Nadi, O. Tavasoli, D. P. N. Kontoni, and A. Tadayon, "Investigation of rock slope stability under pore-water pressure and structural anisotropy by the discrete element method," Geomechanics and Geoengineering, pp. 1-13, 2019.

[16] H. B. Li, J. Zhao, and T. J. Li, "Micromechanical modelling of the mechanical properties of a granite under dynamic uniaxial compressive loads," International Journal of Rock Mechanics and Mining Sciences, vol. 37, no. 6, pp. 923-935, 2000.

[17] X. Zhu and W. Liu, "The rock fragmentation mechanism and plastic energy dissipation analysis of rock indentation," Geomechanics and Engineering, vol. 16, no. 2, pp. 195-204, 2018.

[18] Y. Deng, M. Chen, Y. Jin, and D. Zou, “Theoretical analysis and experimental research on the energy dissipation of rock crushing based on fractal theory," Journal of Natural Gas Science and Engineering, vol. 33, pp. 231-239, 2016.

[19] J. C. Johnson, S. Puvvada, Y. Lu, C. L. Lin, and J. D. Miller, "Energy dissipation and fragmentation of granite core during high velocity impact," Mining, Metallurgy \& Exploration, vol. 36, no. 4, pp. 839-849, 2019.

[20] L. Weng, Z. Wu, Q. Liu, and Z. Wang, "Energy dissipation and dynamic fragmentation of dry and water-saturated siltstones under sub-zero temperatures," Engineering Fracture Mechanics, vol. 220, Article ID 106659, 2019.

[21] Z. X. Zhang, S. Q. Kou, L. G. Jiang, and P.-A. Lindqvist, "Effects of loading rate on rock fracture: fracture characteristics and energy partitioning," International Journal of Rock Mechanics and Mining Sciences, vol. 37, no. 5, pp. 745-762, 2000.

[22] Q. B. Zhang and J. Zhao, "Determination of mechanical properties and full-field strain measurements of rock material under dynamic loads," International Journal of Rock Mechanics and Mining Sciences, vol. 60, pp. 423-439, 2013.

[23] X. B. Li, T. S. Lok, J. Zhao, and P. J. Zhao, "Oscillation elimination in the Hopkinson bar apparatus and resultant complete dynamic stress-strain curves for rocks," International Journal of Rock Mechanics and Mining Sciences, vol. 37, no. 7, pp. 1055-1060, 2000.

[24] X. Li, Z. Zhou, T.-S. Lok, L. Hong, and T. Yin, "Innovative testing technique of rock subjected to coupled static and dynamic loads," International Journal of Rock Mechanics and Mining Sciences, vol. 45, no. 5, pp. 739-748, 2008.

[25] K. Xia, M. H. B. Nasseri, B. Mohanty, F. Lu, R. Chen, and S. N. Luo, "Effects of microstructures on dynamic compression of Barre granite," International Journal of Rock Mechanics and Mining Sciences, vol. 45, no. 6, pp. 879-887, 2008.

[26] R. Chen, K. Xia, F. Dai, F. Lu, and S. N. Luo, "Determination of dynamic fracture parameters using a semi-circular bend technique in split Hopkinson pressure bar testing," Engineering Fracture Mechanics, vol. 76, no. 9, pp. 1268-1276, 2009.
[27] P. Dong, B. Wu, K. Xia, and Q. Wang, "Fracture modes of single-flawed rock-like material plates subjected to dynamic compression," International Journal of Geomechanics, vol. 20, no. 9, pp. 1-13, 2020.

[28] R. Wu, H. Li, and X. Li, "Experimental study and numerical simulation of the dynamic behavior of transversely isotropic phyllite earlybirds," International Journal of Geomechanics, vol. 20, no. 8, pp. 1-16, 2020.

[29] Z. Han, D. Li, T. Zhou, Q. Zhu, and P. G. Ranjith, "Experimental study of stress wave propagation and energy characteristics across rock specimens containing cemented mortar joint with various thicknesses," International Journal of Rock Mechanics and Mining Sciences, vol. 131, Article ID 104352, 2020.

[30] Q. Ping, M. Wu, P. Yuan, H. Su, and H. Zhang, "Dynamic splitting experimental study on sandstone at actual high temperatures under different loading rates," Shock and Vibration, vol. 2020, no. 5, 12 pages, Article ID 8848595, 2020.

[31] L. F. Fan, L. J. Wang, and Z. J. Wu, "Wave transmission across linearly jointed complex rock masses," International Journal of Rock Mechanics and Mining Sciences, vol. 112, pp. 193-200, 2018.

[32] Y. H. Zhang, X. D. Fu, Q. Sheng, and X. L. Leng, "Study on elastic P-wave propagation law in unfavorable geologic structures with discontinuous deformation analysis method," Arabian Journal of Geosciences, vol. 6, no. 11, pp. 4557-4564, 2013.

[33] M. Wang, F. Wang, Z. Zhu, Y. Dong, M. Mousavi Nezhad, and L. Zhou, "Modelling of crack propagation in rocks under SHPB impacts using a damage method," Fatigue \& Fracture of Engineering Materials \& Structures, vol. 42, no. 8, pp. 16991710, 2019.

[34] X.-H. Wang, S.-R. Zhang, C. Wang, C. Shang, K.-L. Cao, and P.-Y. Wei, "Investigation into stress wave propagation across interlayers existing in roller compacted concrete (RCC) under impact loadings," Construction and Building Materials, vol. 193, pp. 13-22, 2018

[35] Y. X. Zhou, K. Xia, X. B. Li et al., "Suggested methods for determining the dynamic strength parameters and mode-I fracture toughness of rock materials," International Journal of Rock Mechanics and Mining Sciences, vol. 49, pp. 105-112, 2012.

[36] L. Wang, Foundations of Stress Waves, Elsevier, Amsterdam, Netherlands, 2011.

[37] P. Wang, J. Xu, X. Fang, and P. Wang, "Energy dissipation and damage evolution analyses for the dynamic compression failure process of red-sandstone after freeze-thaw cycles," Engineering Geology, vol. 221, pp. 104-113, 2017.

[38] S. Liu and J. Xu, "Study on dynamic characteristics of marble under impact loading and high temperature," International Journal of Rock Mechanics and Mining Sciences, vol. 62, pp. 51-58, 2013.

[39] T. Chakraborty, S. Mishra, J. Loukus, B. Halonen, and B. Bekkala, "Characterization of three Himalayan rocks using a split Hopkinson pressure bar," International Journal of Rock Mechanics and Mining Sciences, vol. 85, no. 85, pp. 112-118, 2016. 